\title{
Monitoring of Early Field Hepatic Tolerance to NNRTI-Based Regimens with Multiple Biochemical Parameters in Ivorian HIV-1-Infected Patients: A Pilot Study
}

\author{
Boua Alexis Thierry Kamenan ${ }^{1,2^{*}}$, Danho Pascal Abrogoua ${ }^{1,3}$, Ayoman Thierry Lenoir Djadji, \\ Dagui Monnet ${ }^{2,5}$ \\ ${ }^{1}$ Laboratory of Clinical Pharmacy, Pharmacology and Therapeutics, Faculty of Pharmaceutical and Biological Sciences, University \\ of Cocody-Abidjan, Abidjan, Côte d'Ivoire; ${ }^{2}$ Department of Pharmacy, University Teaching Hospital of Cocody, Abidjan, Côte \\ d'Ivoire; ${ }^{3}$ Department of Clinical Pharmacology, University Teaching Hospital of Cocody, Abidjan, Côte d'Ivoire; ${ }^{4}$ Department of \\ Pharmacy, University Teaching Hospital of Treichville, Abidjan, Côte d'Ivoire; ${ }^{5}$ Laboratory of Clinical Biochemistry, Faculty of \\ Pharmaceutical and Biological Sciences, University of Cocody, Abidjan, Côte d'Ivoire. \\ Email: *dralex_kam@yahoo.fr
}

Received October $8^{\text {th }}, 2011$; revised November $18^{\text {th }}, 2011$; accepted December $10^{\text {th }}, 2011$

\begin{abstract}
Background: Multiple biochemical parameters related to cytolysis, cholestasis and/or liver failure, can be used to evaluate liver tolerance to antiretroviral (ARV) drugs. What parameters are most suitable for monitoring early hepatic tolerance in the developing countries? Objective: To evaluate liver tolerance to NVP (nevirapine) or EFV (efavirenz)based regimens during the first six months. Method: This is a preliminary prospective cohort study with 125 naive ivorian HIV1-infected patients, by observing the level of ALT (alanine aminotransferase), AST (aspartate aminotransferase), ALP (alkaline phosphatase), GGT (gamma-glutamyl transferase), and TBR (total bilirubin). Results: Variable changes are noticed in the level of various biochemical parameters from M0 to M6. Nevertheless, we found that the values of these parameters studied fall within normal ranges except for GGT which showed an increased level with NVP-based regimen. Biological liver tolerance to NVP or EFV-based regimen was good at M3 and M6 during therapy. The percentage of patients who had elevated ALT activity had tripled with each ARV regimen from M3 to M6. We noticed a decrease in the median value of transaminases (ALT and AST) from M0 to M6. This decrease was statistically significant for patients on EFV-based regimen from M0 to M3 and from M0 to M6. The ALP enzymes were the least affected after initiation of therapy, regardless of the regimen taken. In general,we noticed an hepatotoxicity of grade 1 or 2, in the two ARV regimens. The hepatotoxicity of grade 3 or 4 were rare (only with transaminases and GGT). Conclusion: We suggest a study of longer duration involving more patients, probably limited to the monitoring of transaminases (ALT and AST) and GGT, due to the results more or less sensitive about them in our analysis.
\end{abstract}

Keywords: HIV/AIDS; Antiretroviral; Nevirapine; Efavirenz; Hepatic Tolerance; Biochemical Parameters; Abidjan

\section{Introduction}

AIDS remains a public health problem in Côte d'Ivoire with HIV prevalence in the general population estimated to $3.7 \%$ in 2009 [1]. The prescription of antiretroviral drugs (ARVs) in Côte d'Ivoire, as well as biological monitoring of HIV-infected patients, keep to the WHO recommendations in the developing countries [2]. They are based on the prescription of two nucleoside reverse transcriptase inhibitors (NRTIs) and one non-nucleoside reverse transcriptase inhibitor (NNRTI) as first-line anti-

${ }^{*}$ Corresponding author. retroviral therapy (ART) for HIV-1 infection [3]. NNRTIs are very essential and efficient class of ARVs. Efavirenz (EFV) and nevirapine (NVP) are the first-line NNRTIs used in the context of developing countries. NVP since its first description as NNRTI [4] and EFV both have proven efficacy when used in appropriate combinations in ART. Moreover, these two NNRTIs have equal efficiency. A large randomized trial compared EFV and NVP in a tritherapy with stavudine (D4T) and lamivudine (3TC) [5]. This trial showed that the rate of virologic failure was not significantly different in patients receiving NVP compared to those receiving EFV. 
Concerning liver injury, liver is not only a target organ for the virus but also for ART, and hepatobiliary disease is common and sometimes severe in HIV-infected patients [6]. Clinical condition of hepatotoxicity in patients with HIV infection range from asymptomatic increase in transaminases to fulminante liver failure, a severe decomposition of liver function that can lead to death, despite changes or discontinuation of ART. It is associated with symptoms like jaundice, coagulopathy and signifycantly elevated level of alanine aminotransferase (ALT) [7]. The less serious cases of hepatotoxicity associated with ART are generally reversible and are characterized by abnormal serum levels of ALT and/or AST (aspartate aminotransferase) in the presence or not of clinical symptoms of liver injury [8]. The incidence of severe abnormalities of liver function (grade 3 - 4) varies from 2 to 18 per 100 according to different studies [9-11]. This is usually an increased liver enzymes associated or not with a cholestatic syndrome [12]. The increase in liver enzymes was reported as a potential side effect of most ARVs [13-15]. Increase in liver enzymes associated with NNRTIs is sometimes from a hypersensitivity reaction $[16,17]$.

Some reports have linked the use of specific NNRTIs, such as NVP and EFV precisely, to the development of hepatotoxicity [18]. Trials with NVP or EFV have shown acceptable toxicity profiles, pharmacovigilance reports on antiretroviral drugs have identified serious liver injury to nevirapine in particular [10]. Two distinct modes of side effect associated with the use of nevirapine emerged: hypersensitivity reactions and direct drug toxicity [19]. Nevirapine in particular, can cause hepatitis in the first 2 - 3 months of treatment [20]. Conversely, although reported, little published information is available regarding the risk of hepatotoxicity in patients receiving efavirenz $[21,22]$. Early liver abnormalities noticed with efavirenz are usually mild and associated with skin rashes [18]. According to Eholie et al., experiences from the Department of Infectious and Tropical diseases in Abidjan, documentation on adverse effect focused on the fixed combination of D4T + 3TC + NVP, in a study conducted with 282 patients with a prevalence of severe effect of $15.3 \%$ of which $8.2 \%$ are hepatic cytolysis [3]. In the study of Trivacan, tolerance of the combination zidovudine + lamivudine + efavirenz during the first 6 months of treatment was assessed in 740 adults [23]. In those studies, liver problem accounted for one sixth of the rare cases of stopping of EFV.

The two NNRTIs (NVP and EFV) are recommended in resource-limited settings, they can be substituted for one another in case of poor tolerance, like replacing EFV with NVP in the event of persistent and severe toxicity of EFV on the central nervous system, although more sig- nificant skin rashes was noted with NVP than EFV [24]. Similarly, in case of rashes and/or non-severe liver toxicity (grade 1 - 2) associated with the use of NVP, it is recommended to substitute NVP for EFV and make a careful follow-up [2]. Optimum efficiency and good tolerance (e.g. on liver) of first-line ART including NVP or EFV would help to prevent the utilization of the second-line ART that are more expensive.

Abnormalities observed at times in liver function tests, thus necessitate careful interpretation of results. Some drugs (e.g., NVP and less frequently EFV) increase serum levels of gamma-glutamyl transferase (GGT). This laboratory result is often interpreted as a marker of liver injury, an isolated elevation of this enzyme actually reflects enzyme induction. Similarly, hyperbilirubinaemia alone should not be linked to liver injury, as an indirect hyperbilirubinaemia may be related to certain drugs such as indinavir or atazanavir, this risk is increased in patients having underlying Gilbert's syndrome (a genetic disorder) [25-27]. Liver injury induced by drugs is associated with elevated direct bilirubin and clinical jaundice, an appearance of a poor clinical condition. The profile of a cholestasis should not be considered until when there is an associated increase in serum alkaline phosphatase and bilirubin. Elevated transaminase levels should be interpreted in clinical context. For example, increased liver enzymes in a patient with chronic HBV infection do not necessarily imply drug toxicity, but may reflect extended hepatitis $\mathrm{B}$, which often occur during the natural course of the disease [10]. The liver function abnormalities may be due to drug toxicity, but also a lower tolerance of hepatitis B linked to the improvement of cell-mediated immunity to an Hbe-Ag seroconversion or reactivation of hepatitis $B$ virus $[28,29]$.

A laboratory test before starting the first antiretroviral therapy for the determination of transaminases, GGT, alkaline phosphatase (ALP), total bilirubin (TBR) is recommended [12]. However, in resource-limited settings, WHO recommends performing their dosage depending on symptoms. However, some experts suggest monitoring of liver enzymes during the first three months of treatment and then carry out the needed dosage (depending on symptoms) [2].

The first six months of ART is a crucial period for the therapy success, it must be given special attention. Thus, it seemed appropriate to carry out a prospective study during the first 6 months of ART on comparative field hepatic tolerance to NVP and EFV-based regimens. This study is also justified due to the the fact that the predisposing factors for liver toxicity are not automatically given attention to in the developing countries (hepatitis B, hepatitis $\mathrm{C}$, genetic factors ...). With regard to genetic factors, people with HLA-DRB1_0101 have an increased 
propensity to develop hypersensitivity associated with NVP [30-32]. It seems interesting to consider the values of serum transaminases (ALT and AST), TBR, ALP and GGT in patients in Abidjan prior to initiation of treatment and then three months (M3) later and six months (M6) after initiation of ART. This study is a preliminary comparative evaluation approach on biochemical liver tolerance in early stage of NVP or EFV-based regimens. All multiple biochemical parameters related to cytolysis, cholestasis and/or liver failure, not used in routine, will they allow an homogeneous interpretation of liver tolerance in the first six months of ART in Abidjan?

\section{Materials and Methods}

\subsection{Type of Study and Patients}

This is a prospective study, which took place in a certified centre for the care of patients living with HIV/AIDS in the University Teaching Hospital of Cocody-Abidjan (Côte d'Ivoire) in collaboration with the Biochemistry Laboratory of the "Institut Pasteur Cocody-Abidjan". It was conducted with therapy-naive patients before starting this study, infected with human immunodeficiency virus type 1 (HIV-1), aged 15 years minimum, of both sex. We focused on patients receiving NVP or EFVbased regimen. In accordance with the immunological and clinical criteria (CDC classification 1993) [33] and eligibility to ART for adolescents and adults in Côte d'Ivoire [34], we considered asymptomatic patients with CD4 $<200 / \mathrm{mm}^{3}$, symptomatic patients in CDC B stage with CD4 $<350 / \mathrm{mm}^{3}$ and symptomatic patients in CDC $\mathrm{C}$ stage regardless of CD4 cells count. The counting of CD4 cell level was done by using method of flow cytometry. The biomedical data used were those obtained in M0 (prior to initiation of treatment) and those at M3 (third month) and M6 (sixth month) after initiation of ART. Our study included 125 patients (Figure 1).

\subsection{Biochemical Parameters Studied}

The parameters involved in the study were ALT, AST, ALP, GGT and TBR. The biochemical assays were performed on an automatic type Roche Cobas Integra 400 Plus. The analytical methods used were the enzymatic method for ALT and AST, the colorimetric method for ALP and GGT, and diazotization method for TBR. The baseline values of blood biochemical parameters used are those for an Ivorian adult presumed healthy [35]: ALT (6 - $28 \mathrm{IU} / \mathrm{L}), \operatorname{AST}(7-35 \mathrm{IU} / \mathrm{L})$, ALP $(39-210 \mathrm{IU} / \mathrm{L})$,

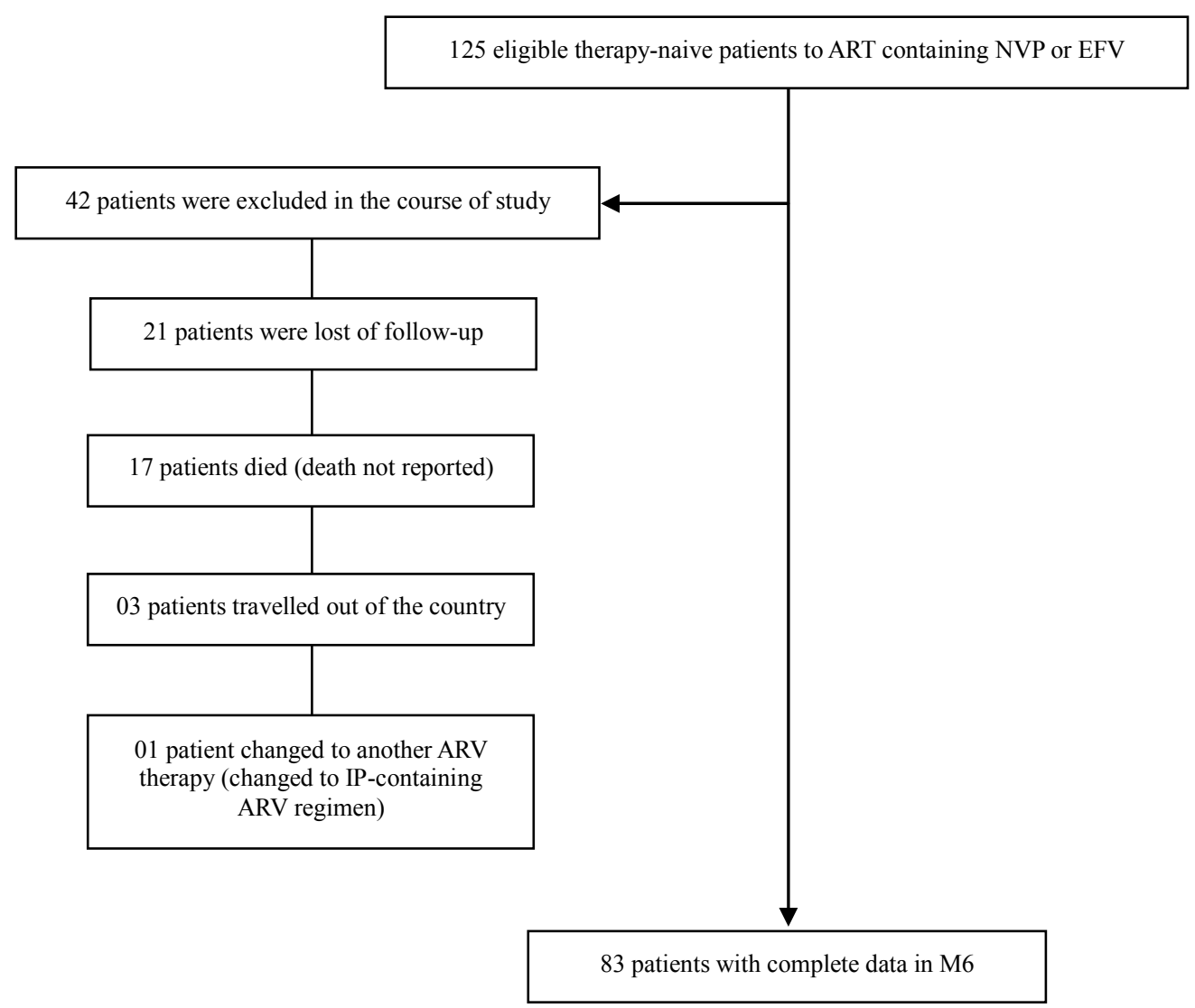

Figure 1. Patients selection diagram. 
GGT ( 8 - $61 \mathrm{IU} / \mathrm{L})$, TBR $(3-13 \mathrm{mg} / \mathrm{L})$. In the first approach of interpretation, these values are considered elevated when above the upper limit normal (ULN). Grades of severity of hepatotoxicity are defined according to WHO [36] from a multiple of the value of the ULN. Thus, we have considered in our study hepatotoxicity to be of grade 1 or 2 when the enzyme activity will be less than $5 \times$ ULN of biochemical parameters. When the enzyme activity will be greater than $5 \mathrm{x}$ ULN of biochemical parameters, we classify hepatotoxicity to be of grade 3 or 4.

\subsection{Statistical Analysis}

Statistical tests used were that of Fisher's exact test and Mann-Whitney test. SPSS version 14.0 software was used for statistical analysis. The level of significance for both tests was $5 \%$.

\section{Results}

\subsection{Analysis of Baseline General Characteristics}

Eighty three patients were retained for our study with a median age of 37 years and $59 \%$ were female. They had a median baseline CD4 count of $101 / \mathrm{mm}^{3}$. Given the antiretroviral regimens studied, these patients were all having HIV-1 infection and more than half had at least one opportunistic infection. The antiretroviral treatment given was the first-line one and consisted of association of 2 NRTIs + 1 NNRTI of either EFV (81.93\%) or NVP (18.07\%). The other main treatment associated with ART was cotrimoxazole prophylaxis and treatment for tuberculosis (TB). All baseline features are presented in Table 1.

\subsection{Analysis of Biochemical Parameters before and after Initiation of ART According to the Type of ARV Regimen (Table 2)}

The monitoring of patients through the two ARV regimens, allowed us to notice an overall decrease in the median values of transaminases (ALT and AST) from M0 to M6. This decrease was statistically significant for patients on EFV-based regimen from M0 to M3 with ALT $(\mathrm{p}<0.001)$ and AST $(\mathrm{p}<0.001)$; and also from M0 to M6 with ALT $(p=0.01)$ and AST $(p=0.001)$. The median values of transaminases in the case of NVP-based regimen remained statistically homogeneous from M0 to M6. Concerning GGT and ALP, the study noted an increase in their median values from M0 to M3 and from M0 to M6 with EFV-based regimen. However, it is necessary to clarify that this increase was significant for GGT from M0 to M3 $(p=0.002)$. The values of GGT and ALP changed variably but remained statistically homogeneous from M0 to M3 and from M0 to M6 with
NVP-based regimen. TBR values decreased significantly from M0 to M3 $(\mathrm{p}=0.008)$ and from M0 to M6 (P = $0.02)$ with EFV-based regimen. Similar evolution concerning TBR was noticed on NVP-based regimen from M0 to M3 $(p=0.02)$ but from M0 to M6 this decrease was not significant $(p=0.12)$. Nevertheless, taking into account the normal values, we found that the hepatic biological tolerance during EFV or NVP-based regimen was generally good in M3 and M6. The majority of the median values of biochemical parameters studied were between normal ranges except for those of GGT that were increased in NVP-based regimen.

\subsection{Comparative Analysis of Biochemical Parameters before and after Initiation of ART between the Two ARV Regimens (Figure 2)}

The comparison of median values of different biochemical parameters after initiation of ART has shown that changes in these parameters were similar in both ARV regimens. All observed differences were not statistically significant $(p>0.05)$. The early hepatic biological tolerance during EFV or NVP-based regimen was generally good and similar. We observed an increase in values of GGT with the NVP-based regimen. But differences observed in M3 and M6 between the median values of this enzyme during EFV-based regimen and NVP-based regimen remained statistically insignificant $(p>0.05)$ even though they had been in M0 $(p=0.03)$.

\subsection{Comparative Analysis of Early Hepatic Biochemical Changes after Initiation of NVP and EFV-Based Regimens}

According to the two ARV regimens studied, no significant difference was observed in the proportion of patients

Table 1. Baseline characteristics.

\begin{tabular}{|c|c|c|}
\hline \multirow{3}{*}{$\begin{array}{l}\text { Age at the beginning of } \\
\text { treatment (years) }\end{array}$} & Median (IQR) & $37(32-44)$ \\
\hline & $<50$ & $69(83.13 \%)$ \\
\hline & $\geq 50$ & $14(16.87 \%)$ \\
\hline \multicolumn{2}{|c|}{ Female } & $49(59 \%)$ \\
\hline HIV Type & HIV1 [n(\%)] & $83(100 \%)$ \\
\hline baseline $\mathrm{CD} 4$ count $\left(/ \mathrm{mm}^{3}\right)$ & Median (IQR) & $101(01-363)$ \\
\hline \multicolumn{2}{|c|}{ Presence of opportunistic infection [n(\%)] } & $50(60.24 \%)$ \\
\hline \multirow{2}{*}{ Antiretroviral Therapy } & NVP-based regimen $[\mathrm{n}(\%)]$ & $15(18.07 \%)$ \\
\hline & EFV based-regimen $[n(\%)]$ & $68(81.93 \%)$ \\
\hline \multicolumn{2}{|c|}{ Cotrimoxazole prophylaxis $[\mathrm{n}(\%)]$} & $73(87.95 \%)$ \\
\hline \multicolumn{2}{|c|}{ TB treatment $[\mathrm{n}(\%)]$} & $10(12.05 \%)$ \\
\hline
\end{tabular}


Table 2. Values of various biochemical parameters in M3 and M6 compared to the value in M0 for patients on NVP or EFVbased regimen.

\begin{tabular}{|c|c|c|c|c|c|}
\hline & \multirow{2}{*}{ Biochemical Parameters } & \multicolumn{4}{|c|}{ [Median (IQR)] } \\
\hline & & M0 & M3 & M0 & M6 \\
\hline \multirow{10}{*}{$\begin{array}{l}\text { NVP-based regimen } \\
\quad(\mathrm{n}=15)\end{array}$} & ALT & $18.6(14.5-28.1)$ & $15.7(8.8-27.3)$ & $18.6(14.5-28.1)$ & $23.5(14.25-29.85)$ \\
\hline & $\mathrm{p}$ & \multicolumn{2}{|c|}{0.16} & \multicolumn{2}{|c|}{0.36} \\
\hline & AST & $32.2(29.3-45.2)$ & $27.3(21.7-45.1)$ & $32.2(29.3-45.2)$ & $28(23.8-42.5)$ \\
\hline & $\mathrm{p}$ & \multicolumn{2}{|c|}{0.05} & \multicolumn{2}{|c|}{0.41} \\
\hline & ALP & $85.4(71.1-126)$ & $110(77.2-135)$ & $85.4(71.1-126)$ & $104(82.7-125$ \\
\hline & $\mathrm{p}$ & \multicolumn{2}{|c|}{0.14} & \multicolumn{2}{|c|}{0.28} \\
\hline & GGT & $81.1(40.3-159)$ & $69.3(53.7-186)$ & $81.1(40.3-159)$ & $67.5(39.6-134$ \\
\hline & $\mathrm{p}$ & \multicolumn{2}{|c|}{0.73} & \multicolumn{2}{|c|}{0.86} \\
\hline & TBR & $6(4-7)$ & $4(4-6)$ & $6(4-7)$ & $4(4-6)$ \\
\hline & $\mathrm{p}$ & 0 . & & 0 . & \\
\hline \multirow{10}{*}{$\begin{array}{l}\text { EFV-based regimen } \\
\qquad(\mathrm{n}=68)\end{array}$} & ALT & $26.4(15.25-34.22)$ & $14.3(8.750-18.30)$ & $26.4(15.25-34.22)$ & $15.9(12.55-27.2)$ \\
\hline & $\mathrm{p}$ & \multicolumn{2}{|c|}{$<0.001$} & \multicolumn{2}{|c|}{0.01} \\
\hline & AST & $37.65(26.70-54.8)$ & $26.45(21.35-34.77)$ & $37.65(26.70-54.8)$ & $27.60(22.62-35.45)$ \\
\hline & $\mathrm{p}$ & \multicolumn{2}{|c|}{$<0.001$} & \multicolumn{2}{|c|}{0.001} \\
\hline & ALP & $87.35(68.85-117.75)$ & $96.35(71.35-126.75)$ & $87.35(68.85-117.75)$ & $105.5(72.57-134)$ \\
\hline & $\mathrm{p}$ & \multicolumn{2}{|c|}{0.32} & \multicolumn{2}{|c|}{0.06} \\
\hline & GGT & $41(29.3-74.67)$ & $52.4(37.25-117)$ & $41(29.3-74.67)$ & $43.05(30.42-73.6)$ \\
\hline & $\mathrm{p}$ & \multicolumn{2}{|c|}{0.002} & \multicolumn{2}{|c|}{0.66} \\
\hline & TBR & $5(3-6)$ & $4(3-5)$ & $5(3-6)$ & $4(3-5)$ \\
\hline & $\mathrm{p}$ & \multicolumn{2}{|c|}{0.008} & \multicolumn{2}{|c|}{0.02} \\
\hline
\end{tabular}

p Mann-Whitney test.

who experienced an increase in enzyme activity $(p>0.05)$ in M3 and M6. No changes in TBR values were found in M3 and M6 with the two ARV regimens. We also found that the proportion of patients who had elevated ALT activity have increased approximately from $8 \%$ to $24 \%$ for EFV-based regimen and from $6 \%$ to $20 \%$ for the NVP-based regimen (Figure 3). ALP enzymes are the least affected after initiation of ART regardless of ARV regimen. Indeed only $8.8 \%$ of patients under EFV-based regimen and $6.6 \%$ of patients on NVP-based regimen showed an increase in the activity of ALP in M3. In M6, $7.3 \%$ of patients receiving EFV-based regimen had a higher activity of ALP and no changes in the activity of this enzyme was observed with NVP-based regimen. Overall hepatotoxicity observed were grade 1 or 2 and was similar for the two regimens, with no statistically significant differences $(p>0.05)$ with all the enzymes studied in M3 and M6. The hepatotoxicity of grade 3 or 4 were rare (only with transaminases and GGT) and no significant differences were observed in M3 and M6 between the two ARV regimens (Table 3).

\subsection{Increases in Serum Level of Biochemical Parameters in M6 According to ARV Regimen and Considering Certain Particular Factors}

By studying increases in biochemical parameters serum level in M6 according to certain predisposing factors to liver toxicity, we have discovered that gain in CD4 cells and baseline CD4 count in NVP-based regimen have no influence on these increases (Fisher's exact test $p>0.05$ ). However, TB treatment with EFV-based regimen had significant effect on the increase of GGT in M6 (Fisher 


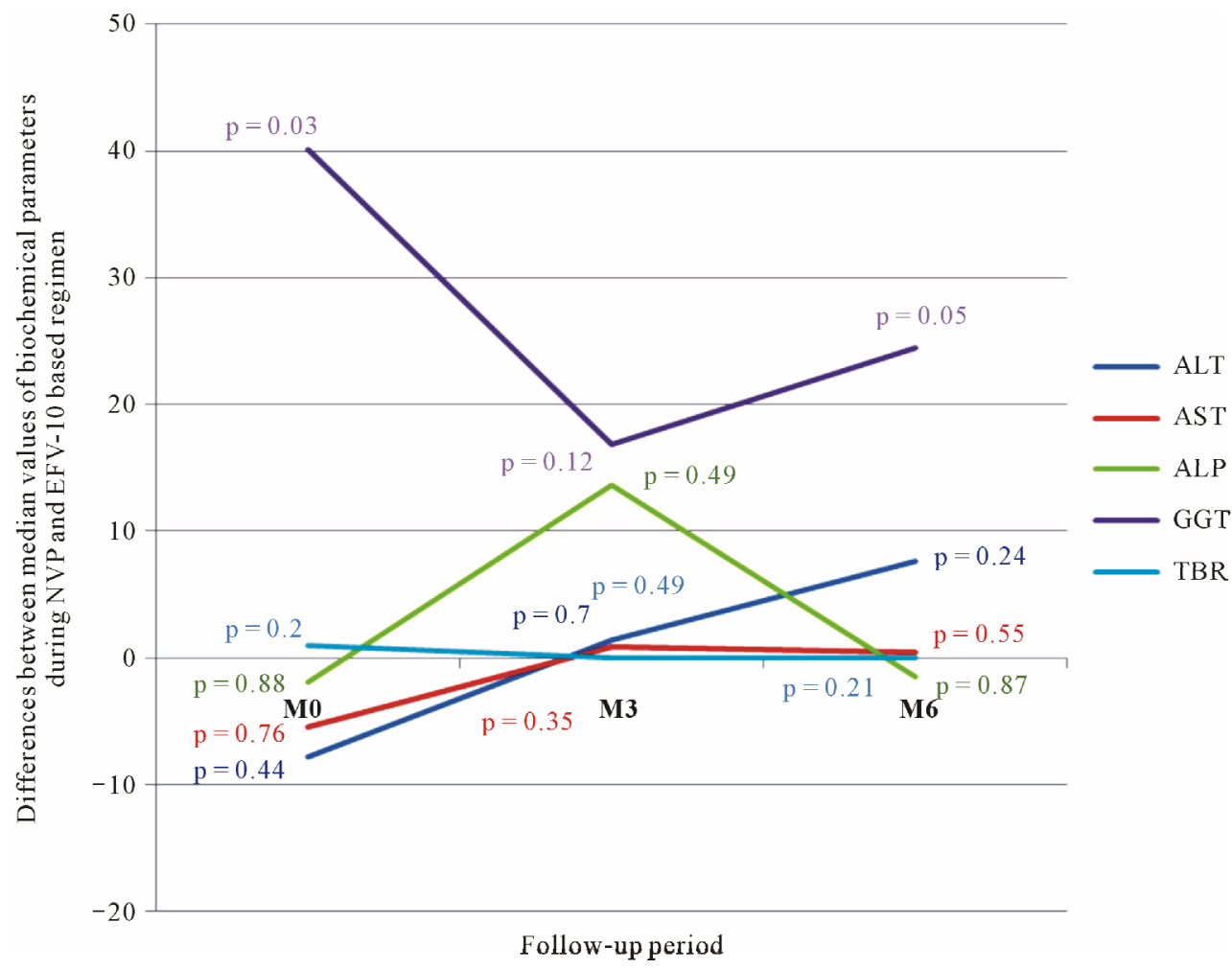

Figure 2. Differences between median values of biochemical parameters during NVP and EFV-based regimen (p MannWhitney test).

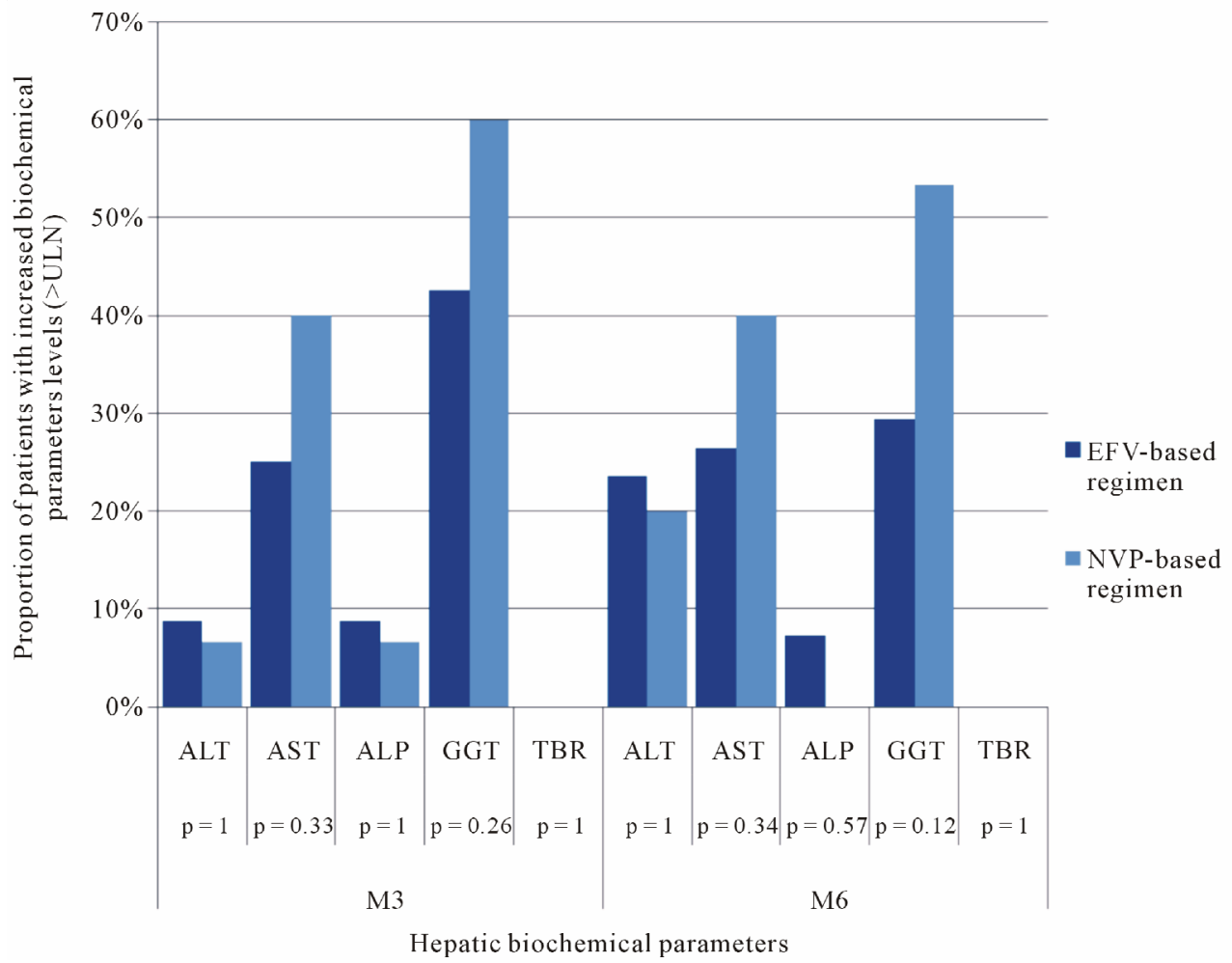

Figure 3. Proportion of patients who experienced an increase in biochemical parameters (>NUL) according to ARV regimens (p Fischer's exact test). 
Table 3. Comparison of the increase in biochemical parameters based on the grades between the two regimes ARV.

\begin{tabular}{|c|c|c|c|c|c|c|c|c|c|c|c|}
\hline & & \multicolumn{5}{|c|}{ M3 [n (\%)] } & \multicolumn{5}{|c|}{ M6 [n (\%)] } \\
\hline & & ALT & AST & ALP & GGT & TBR & ALT & AST & ALP & GGT & TBR \\
\hline \multirow{3}{*}{$\begin{array}{l}\text { Hepatotoxicity of } \\
\text { grade } 1 \text { or } 2\end{array}$} & $\begin{array}{c}\text { EFV-based } \\
\text { regimen }(n=68)\end{array}$ & $\begin{array}{c}5 \\
(7.3 \%)\end{array}$ & $\begin{array}{c}16 \\
(23.6 \%)\end{array}$ & $\begin{array}{c}6 \\
(8.8 \%)\end{array}$ & $\begin{array}{c}22 \\
(32.3 \%)\end{array}$ & $\begin{array}{c}0 \\
(0 \%)\end{array}$ & $\begin{array}{c}15 \\
(22.1 \%)\end{array}$ & $\begin{array}{c}18 \\
(26.4 \%)\end{array}$ & $\begin{array}{c}5 \\
(7.3 \%)\end{array}$ & $\begin{array}{c}15 \\
(22.1 \%)\end{array}$ & $\begin{array}{c}0 \\
(0 \%)\end{array}$ \\
\hline & $\begin{array}{l}\text { NVP-based } \\
\text { regimen }(n=15)\end{array}$ & $\begin{array}{c}1 \\
(6.6 \%)\end{array}$ & $\begin{array}{c}6 \\
(40 \%)\end{array}$ & $\begin{array}{c}1 \\
(6.6 \%)\end{array}$ & $\begin{array}{c}7 \\
(46.6 \%)\end{array}$ & $\begin{array}{c}0 \\
(0 \%)\end{array}$ & $\begin{array}{c}3 \\
(20 \%)\end{array}$ & $\begin{array}{c}6 \\
(40 \%)\end{array}$ & $\begin{array}{c}0 \\
(0 \%)\end{array}$ & $\begin{array}{c}6 \\
(40.6 \%)\end{array}$ & $\begin{array}{c}0 \\
(0 \%)\end{array}$ \\
\hline & $\mathrm{p}$ & 1 & 0.20 & 1 & 0.37 & 1 & 1 & 0.34 & 0.57 & 0.19 & 1 \\
\hline \multirow{3}{*}{$\begin{array}{l}\text { Hepatotoxicity of } \\
\text { grade } 3 \text { or } 4\end{array}$} & $\begin{array}{c}\text { EFV-based } \\
\text { regimen }(n=68)\end{array}$ & $\begin{array}{c}1 \\
(1.4 \%)\end{array}$ & $\begin{array}{c}1 \\
(1.4 \%)\end{array}$ & $\begin{array}{c}0 \\
(0 \%)\end{array}$ & $\begin{array}{c}5 \\
(7.3 \%)\end{array}$ & $\begin{array}{c}0 \\
(0 \%)\end{array}$ & $\begin{array}{c}1 \\
(1.4 \%)\end{array}$ & $\begin{array}{c}0 \\
(0 \%)\end{array}$ & $\begin{array}{c}0 \\
(0 \%)\end{array}$ & $\begin{array}{c}5 \\
(7.3 \%)\end{array}$ & $\begin{array}{c}0 \\
(0 \%)\end{array}$ \\
\hline & $\begin{array}{l}\text { NVP-based } \\
\text { regimen }(n=15)\end{array}$ & $\begin{array}{c}0 \\
(0 \%)\end{array}$ & $\begin{array}{c}0 \\
(0 \%)\end{array}$ & $\begin{array}{c}0 \\
(0 \%)\end{array}$ & $\begin{array}{c}2 \\
(1.3 \%)\end{array}$ & $\begin{array}{c}0 \\
(0 \%)\end{array}$ & $\begin{array}{c}0 \\
(0 \%)\end{array}$ & $\begin{array}{c}0 \\
(0 \%)\end{array}$ & $\begin{array}{c}0 \\
(0 \%)\end{array}$ & $\begin{array}{c}2 \\
(1.3 \%)\end{array}$ & $\begin{array}{c}0 \\
(0 \%)\end{array}$ \\
\hline & $\mathrm{p}$ & 1 & 1 & 1 & 0.60 & 1 & 1 & 1 & 1 & 0.60 & 1 \\
\hline
\end{tabular}

p Fischer's exact test.

test $\mathrm{p}=0.005)$. The increase in other biochemical parameters serum level with this regimen was not influenced by the others factors cited above (Fisher's exact test $\mathrm{p}>0.05)$.

\section{Discussion}

Non-Nucleoside Reverse Transcriptase Inhibitors like NVP and EFV are often used in combination with other ARVs for the treatment of HIV-1 infection. However, significant hepatotoxicity was observed with their use in clinical trials and in practice [37-40]. In our study, the evolution of various biochemical parameters from M0 to M6 is variable with NVP or EFV-based regimen. However, we found that the majority of values of these parameters studied fell within the normal ranges except for that of GGT that was increased during NVP-based regimen. Comparing the values of these biochemical parameters during ART, we found that the hepatic biological tolerance to EFV or NVP-based regimen was generally good and similar in M3 and M6: no significant difference has been observed in the proportion of patients who experienced an increase in enzyme activities between these two ARV regimens. Palmon et al. in their retrospective cohort study determined the incidence of hepatotoxicity associated with NNRTI in a group of HIV-infected patients who received delavirdine, EFV and NVP, the rate was similar among the three treatment groups [41]. Other results were provided by Sanne et al. in early hepatotoxicity (during the first 12 weeks of treatment). In their analysis, the frequency of hepatotoxicity was $17 \%$ in the group receiving NVP and $0 \%$ in the EFV group [42]. Their data confirmed an increased risk of early hepatotoxicity associated with the use of NVP $[11,43]$. The proportion of patients who had elevated
ALT activity had tripled with each ARV therapy from M3 to M6. The increased activity of ALT was reported as a potential side effect of most ARVs used in the treatment of HIV infection [44,45]. Our study findings are close to those of Martinez et al. who showed in a study on the occurrence of skin reactions or liver injury after receiving NVP, that hepatotoxicity was observed in $12.5 \%$ of their cohort with an incidence of $3 \%$ and $9 \%$ in M3 and M6 respectively [37].

Our study showed an overall decrease in median value of transaminases (ALT and AST) from M0 to M6. This decrease was statistically significant for patients receiving EFV-based regimen from M0 to M3 and M0 to M6. Sulkowski et al. found no difference in ALT and AST serum levels before treatment between patients who received NVP or EFV like in our study. However, during follow-up, the magnitude of the increase in ALT and AST serum levels was higher in patients who received NVP compared to those receiving EFV with a follow-up period longer than ours [18]. These authors acknowledged that the increased levels of ALT or AST are imperfect indicators of hepatotoxicity, but said they are commonly used in clinical practice [46]. The ALP enzymes were the least affected after initiation of ARV treatment regardless of ARV regimen. After six months of treatment, only $7 \%$ of patients receiving EFV-based regimen had a higher activity of ALP. Djoman et al. [45] observed in their study $1.7 \%$ of cases of elevated ALP over a period of six months of ART in Abidjan. Overall hepatotoxicity observed was grade 1 or 2 and was similar for the two ART containing EFV or NVP. The hepatotoxicity of grade 3 or 4 were rare (only with transaminases and GGT) and no significant differences were observed in M3 and M6 between the two ARV regimens. Palmon et al. also showed a low incidence of grade 3-4 
hepatotoxicity (1.1\%) especially with ALT and AST by comparing treatments based on delarvidine, efavirenz or nevirapine [41]. Reisler et al. also reported in a metaanalysis from laboratory data and mortality of 21 clinical studies of "AIDS Clinical Trial Group" (ACTG), that ART consisting of two NRTIs and NVP or EFV were associated with ALT and/or AST levels greater than five times the ULN ( $8.9 \%$ and $10.8 \%$ respectively) that were not significantly different [22]. Similarly, in a cohort study that compared liver tolerance when receiving NNRTIs with 3975 person per years with good follow-up, there was no significant difference between ALT and/or AST levels greater than 5 times the ULN in patients treated with NVP or EFV (2.1\% and $1.7 \%$ respectively) [47]. But Sulkowski et al. concluded in their study that severe hepatotoxicity occurs during one NNRTI-based therapy and was more common in patients receiving NVP (occurring in 15.6\%) than those using the EFV (8\%) over a relatively longer period [18]. The relatively high rate of severe hepatotoxicity observed by Sulkowski et al. compared with those previously reported in clinical trial cohorts, could be explained by the high incidence of factors that could lead to the hepatotoxicity of NNRTIs such as chronic hepatitis [18]. By studying the biochemical parameters median increases in M6 based on certain factors predisposing to liver toxicity, we found no influence of the gain of CD4 cells count, sex and initial CD4 count with NVP-based regimen. Only the influence of TB treatment with EFV-based regimen had significantly increased GGT in M6.

A significant increase in the value of GGT was noticed three months after starting treatment with EFV. This elevation of GGT could be explained by the phenomenon of enzyme induction of anti-tuberculosis drugs (rifampicin, isoniazid) because 8 out of 10 patients who were under TB treatment had high GGT serum level. Our results are similar to those of Pozniak et al. who observed in a study that the side effects of anti-tuberculosis drugs on the liver is observed in $20 \%-40 \%$ of patients with HIV infection and occurred in the first six months of treatment [48]. TB treatment would be a predictive factor of the occurrence of cholestasis in patients receiving ART containing EFV. The taking of anti-tuberculosis drugs by patients would play an important role.

Indeed the enzyme induction caused by rifampicin would cause increased GGT levels and incidence of severe abnormalities of liver function (grade 3 - 4) varies from $2 \%$ to $18 \%$ in some studies $[9,11]$. Analyses of hepatic side effects from other cohorts, such as "CHORUS" (Collaborations in HIV Outcomes Research U.S.) and "Target studies" have confirmed that the frequency and the risk of significant hepatic events with NVP or EFVbased regimen were similar to those associated with the use of other ARVs [49-52]. Clarke et al. have reported that some patients who experienced serious liver toxicity with NVP did not develop severe hepatotoxicity during a subsequent treatment with $\mathrm{EFV}$, suggesting that toxicity was related to ARV and not to specific class [53]. It should be noted that hepatotoxicity with NVP or EFV does not appear to increase the risk of developing liver damage from exposure to alternative NNRTIs [54,55].

\section{Conclusion}

This study about the prospective monitoring of early field hepatic tolerance to NVP or EFV-based regimens is a preliminary analysis. Monitoring of multiple biochemical parameters showed a good liver tolerance to these two ARV regimens in the first six months of therapy. A study of longer duration with more patients probably restricted to the monitoring of transaminases (ALT and AST) and GGT, due to the results more or less sensitive about them in our study. A correlation of changes in these biochemical parameters to more factors (presence or absence of hepatitis, tuberculosis treatment, and baseline CD4 count, female and others predisposing factors of liver toxicity) is essential for a better interpretation of hepatic tolerance in Ivorian HIV1-infected patients, receiving prefered first-line ART in developing countries. A good monitoring of first-line ART could prevent the second-line ART which is more expensive.

\section{REFERENCES}

[1] ONUSIDA, "Rapport mondial sur l'épidémie du sida," 2009.

[2] OMS, Organisation Mondiale de la Santé, "Traitement Antirétroviral de l'Infection à VIH Chez l'Adulte et l'Adolescent en Situation de Ressources Limitées: Vers un Accès Universel," Recommandations pour une approche de santé publique, Version 2006, Genève WC 503.2, 2008.

[3] S. P. Eholié, K. A. Tanon, M. Folquet-Amorissani, I. Ouattara, Y. T. Aba, V. Traoré-Ettiegne, et al., "Bilan de l'Accès aux Antirétroviraux en Côte d'Ivoire," Médecine Tropicale, Vol. 69, No. 5, 2009, pp. 520-524.

[4] V. J. Merluzzi, K. D. Hargrave, M. Labadia, et al., "Inhibition of HIV-1 Replication by a Non-Nucleoside Reverse Transcriptase Inhibitor," Science, Vol. 250, No. 4986, 1990, pp. 1411-1413. doi:10.1126/science. 1701568

[5] F. V. L. Eth, P. Hanuphak, R. K. Uxrungtham, et al., "Comparison of First-Line Antiretroviral Therapy with Regimens Including Nevirapine, Efavirenz, or Both Drugs, plus Stavudine and Lamivudine: A Randomised Open-Label Trial, the 2NN Study," Lancet, Vol. 363, No. 9417, 2004, pp. 1253-1263. doi:10.1016/S0140-6736(04)15997-7 
[6] R. M. Selik, R. H. Byers Jr. and M. S. Dworkin, “Trends in Diseases Reported on US Death Certificates That Mentioned HIV Infection, 1987-1999," Journal of Acquired Immune Deficiency Syndromes, Vol. 29, No.4, 2002, pp. 378-387.

[7] A. Shakil, D. Kramer, G. Mazariegos, J. J. Fung and J. Rakela, "Acute Liver Failure: Clinical Features, Outcome Analysis, and Applicability of Prognostic Criteria," Liver Transplantation, Vol. 6, No. 2, 2000, pp. 163-169.

[8] H. Zimmerman, "Drug-Induced Liver Disease," In: E. Schiff, W. Sorrell and W. Muldrey, Eds., Schiff's Diseases of the Liver, 8th Edition, Lippincott-Raven Publishers, Philadelphia, 1999, pp. 973-1064.

[9] J. Servoss, D. Kitch, J. Andersen, et al., "Predictors of Antiretroviral-Related Hepatotoxicity in the Adult AIDS Clinical Trial Group (1989-1999)," Journal of Acquired Immune Deficiency Syndromes, Vol. 43, No. 3, 2006, pp. 320-323. doi:10.1097/01.qai.0000243054.58074.59

[10] V. Soriano, M. Puoti, P. Garcia-Gasco, J. K. Rockstroh, Y. Benhamou, P. Barreiro and B. McGovern, "Antiretroviral Drugs and Liver Injury," AIDS, Vol. 22, No. 1, 2008, pp. 1-13. doi:10.1097/QAD.0b013e3282f0e2fd

[11] F. W. N. M. Wit, G. J. Weverling, J. Weel, S. Jurriaans and J. M. A. Lange, "Incidence and Risk Factors For severe Hepatotoxicity Associated with Antiretroviral Therapy," Journal of Infectious Diseases, Vol. 186, No.1, 2002, pp. 23-31. doi:10.1086/341084

[12] P. Yeni, "Prise en Charge des Personnes Infectées par le VIH: Recommandations du Groupe d'Experts," Médecine-Sciences, Paris, Flammarion, 2008, 412 Pages.

[13] E. Gisolf, C. Dreezen and S. Danner, "Risk Factors for Hepatoxicity in HIV-1 Infected Patients Receiving Ritonavir and Saquinavir with or without Stavudine," Clinical Infectious Diseases, Vol. 31, No. 1, 2000, pp. 1234-1239. doi:10.1086/317449

[14] B. Kees, J. M. Hadewych and H. Ter, “Adverse Effects of Reverse Transcriptase Inhibitors: Mitochondrial Toxicity as Common Pathway," Journal of Acquired Immune Deficiency Syndromes, Vol. 12, No. 14, 1998, pp. 17351744.

[15] V. Montessori, N. Press, M. Harris, L. Akagi and S. Montaner, "Adverse Effects of Antiretroviral for HIV Infection," Canadian Medical Association Journal, Vol. 170, No. 2, 2004, pp. 229-238.

[16] A. M. Cattelan, E. Erne, A. Saltino, et al., "Severe Hepatic Failure Related to Nevirapine Treatment," Clinical Infectious Diseases, Vol. 29, No. 2, 1999, pp. 455-456. doi:10.1086/520242

[17] P. Bossi, D. Colin, F. Bricaire and E. Caumes, "Hypersensitivity Syndrome Associated with Efavirenz Therapy," Clinical Infectious Diseases, Vol. 30, No. 1, 2000, pp. 227-228. doi: $10.1086 / 313629$

[18] M. S. Sulkowski, D. L. Thomas, S. H. Mehta, R. E. Chaisson and R. D. Moore, "Hepatotoxicity Associated with Nevirapine or Efavirenz-Containing Antiretroviral Therapy: Role of Hepatitis C and B Infections," Hepatology, Vol. 35, No. 1, 2002, pp. 182-189.

\section{doi:10.1053/jhep.2002.30319}

[19] D. Gonzalez de Requena, M. Nunez, I. Jimenez-Nacher and V. Soriano, "Liver Toxicity Caused by Nevirapine," AIDS, Vol. 16, No.2, 2002, pp. 290-291. doi:10.1097/00002030-200201250-00020

[20] Boehringer-Ingelheim International Viramune product monograph, version 3.0, Ingelheim am Rhein, BoehringerIngelheim International $\mathrm{GmbH}$, Germany.

[21] R. Verdon, M. Six, P. Rousselot and C. Bazin, "Efavirenz-Induced Acute Eosinophilic Hepatitis," Journal of Hepatology, Vol. 34, 2001, No. 5, pp. 783-785.

[22] R. Reisler, S. Liou, J. Servoss, G. Robbins, D. Theodore, R. Murphy and R. Chung, "Incidence of Hepatotoxicity and Mortality in 21 Adult Antiretroviral Treatment Trials [Abstract 43]," 1st International AIDS Society on HIV Pathogenesis and Treatment, 8-11 July 2001, Buenos Aires, Argentina.

[23] C. Danel, R. Moh, A. Anzian, Y. Abo, H. Chenal, C. Guehi, et al., "Tolerance and Acceptability of an Efavirenz-Based Regimen in 740 Adults (Predominantly Women) in West Africa," Journal of Acquired Immune Deficiency Syndromes, Vol. 42, No. 1, 2006, pp. 29-35. doi:10.1097/01.qai.0000219777.04927.50

[24] F. V. L. Eth, S. Andrews, B. Grinsztejn, et al., "The Effect of Baseline CD4 Cell Count and HIV-1 Viral Load on The Efficacy and Safety of Nevirapine or EfavirenzBased First-Line HAART," AIDS, Vol. 19, No. 5, 2005, pp. 463-447. doi:10.1097/01.aids.0000162334.12815.5b

[25] S. Zucker, X. Qin, S. Rouster, F. Yu, R. Green, P. Keshavan, et al., "Mechanism of Indinavir-Induced Hyperbilirubinemia," Proceedings of the National Academy of Sciences of the United States of America, Vol. 98, 2001, No. 22, pp. 12671-12676.

[26] S. Rodriguez-Novoa, P. Barreiro, A. Rendon, A. Barrios, A. Corral, I. Jimenez-Nacher, et al., "Plasma Levels of Atazanavir and the Risk of Hyperbilirubinemia Are Predicted by the 3435C-T Polymorphism at the Multidrug Resistance Gene 1," Clinical Infectious Diseases, Vol. 42, No. 2, 2006, pp. 291-295. doi:10.1086/499056

[27] T. Lankisch, U. Moebius, M. Wehmeier, G. Behrens, M. Manns, R. Schmidt, et al., "Gilbert's Disease and Atazanavir: From Phenotype to UDP-Glucuronosyltransferase Haplotype," Hepatology, Vol. 44, No. 5, 2006, pp. 1324-1332. doi:10.1002/hep.21361

[28] P. Miailhes, M. Trabaud, P. Pradat, et al., "Impact of Highly Active Antiretroviral Therapy (HAART) on the Natural History of Hepatitis B Virus (HBV) and HIV Co-Infection: Relationship between Prolonged Efficacy of HAART and HBV Surface and Early Antigen Seroconversion," Clinical Infectious Diseases, Vol. 45, No. 5, 2007, pp. 624-632. doi:10.1086/520752

[29] O. Chauvel, K. Lacombe, P. Bonnard, et al., "Risk Factors for Acute Liver Enzyme Abnormalities in HIV Hepatitis B Virus-Coinfected Patients on Antiretroviral Therapy," Antiviral Therapy, Vol. 12, No. 7, 2007, pp. 11151126.

[30] M. De Maat, R. Mathot, A. Veldkamp, A. Huitma, J. Mulder, P. Meenhorst, et al., "Hepatotoxicity Following 
Nevirapine Containing Regimens in HIV-1-Infected Individuals," Pharmacological Research, Vol. 46, No. 3, 2002, pp. 295-300. doi:10.1016/S1043-6618(02)00146-9

[31] A. Martin, D. Nolan, I. James, P. Cameron, J. Keller, C. Moore, et al., "Predisposition to Nevirapine Hypersensitivity Associated with HLA-DRB1M0101 and Abrogated by Low CD4 T-Cell Counts," AIDS, Vol. 19, No. 13, 2005, pp. 97-99.

doi:10.1097/00002030-200501030-00014

[32] S. Johnson, J. Chan and C. Bennett, "Hepatotoxicity after Prophylaxis with a Nevirapine-Containing Antiretroviral Regimen," Annals of Internal Medicine, Vol. 137, No. 2, 2002, pp. 146-147.

[33] CDC, "1993 Revised Classification System for HIV Infection and expanded Surveillance Case Definition for AIDS among Adolescents and Adults-M.M.W.R.," 41, No-RR17, 1992.

[34] S. P. Eholié and P. M. Girard, "Mémento thérapeutique du VIH/sida en Afrique," Doin, Paris, 2005.

[35] A. Yapo, M. Assayi, N. Aka, R. Bonetto, L. Comoe, A. Lonsdorfer, D. Monnet and C. Diane, "Les valeurs de références de 21 constituants biochimiques sanguins de l'Ivoirien adulte présumé sain," Publications méDicales Africaines, Vol. 110, 1990, pp. 49-57.

[36] OMS, "Grades de sévérité de certaines toxicités cliniques et biologiques," Adapté à partir de documents de la Division of AIDS, National Institute of Allergy and Infectious Diseases, USA. In Traitement antirétroviral de l'infection à VIH chez l'adulte et l'adolescent en situation de ressources limitées: vers un accès universel, Recommandations pour une approche de santé publique, Version 2006, Genève WC 503.2, 2008, pp. 102-106.

[37] E. Martinez, J. L. Blanco, J. A. Arnaiz, J. B. PerezCuevas, A. Mocroft, A. Cruceta, M. A. Marcos, et al., "Hepatotoxicity in HIV-1-Infected Patients Receiving Nevirapine-Containing Antiretroviral Therapy," AIDS, Vol. 15, No. 10, 2001, pp. 1261-1268. doi:10.1097/00002030-200107060-00007

[38] G. M. Lucas, R. E. Chaisson and R. D. Moore, "Comparison of initial Combination Antiretroviral Therapy with a Single Protease Inhibitor, Ritonavir and Saquinavir, or Efavirenz," AIDS, Vol. 15, No. 13, 2001, pp. 16791686. doi:10.1097/00002030-200109070-00011

[39] G. Moyle, "The Emerging Roles of Non-Nucleoside Reverse Transcriptase Inhibitors in Antiretroviral Therapy," Drugs, Vol. 61, No. 1, 2001, pp. 19-26. doi:10.2165/00003495-200161010-00003

[40] G. Peytavin, R. Landman, C. Lamotte, A. Trylesinski, S. Legac, F. Mentre and P. Yeni, "Therapeutic Drug Monitoring of Nelfinavir in a Prospective Study in HIV-HCV Coinfected Patients with Chronic Liver Disease [Abstract 349]," 1st International AIDS Society on HIV Pathogenesis and Treatment, 8-11 July 2001, Buenos Aires.

[41] R. Palmon, B. C. Koo, D. A. Shoultz and D. T. Dieterich, "Lack of Hepatotoxicity Associated with Nonnucleoside Reverse Transcriptase Inhibitors," Journal of Acquired Immune Deficiency Syndromes, Vol. 29, No. 4, 2002, pp. 340-345.
[42] I. Sanne, H. Mommeja-Marin, J. Hinkle, J. A. Bartlett, M. M. Lederman, G. Maartens, C. Wakeford, A. Shaw, J. Quinn, R. G. Gish and F. Rousseau, "Severe Hepatotoxicity Associated with Nevirapine Use in HIV-Infected Subjects," Journal of Infectious Diseases, Vol. 191, No. 6, 2005, pp. 825-829. doi:10.1086/428093

[43] W. M. Lee, "Drug-Induced Hepatotoxicity," New England Journal of Medicine, Vol. 349, No. 5, 2003, pp. 474-485. doi:10.1056/NEJMra021844

[44] M. Sulkowski, D. Thomas, R. Chaisson and R. Moore, "Hepatotoxicity Associated with Antiretroviral Therapy in Adult with Human Immunodeficiency Virus and the Role of Hepatitis C or B Virus Infection," Journal of the American Medical Association, Vol. 283, No. 1, 2000, pp. 74-80. doi:10.1001/jama.283.1.74

[45] G. Djoman, T. Roel, T. Ellerbrock, D. Hanson, F. Diomande and A. Kadio, "Virologic and Immunologic Outcomes and Programmatic Challenge of an Antiretroviral Treatment Pilot Project in Abidjan Côte d'Ivoire," Journal of Acquired Immune Deficiency Syndromes, Vol. 17, No. 3, 2003, pp. 5-15.

[46] M. S. Sulkowski, D. L. Thomas, S. H. Mehta, R. E. Chaisson and R. D. Moore, "Reply to 'NNRTI-Related or Unrelated Hepatotoxicity' [Letter]," Hepatology, Vol. 36, No. 2, 2002, pp. 513-514. doi:10.1053/jhep.2002.34940

[47] N. Friis-Moller, O. Kirk, P. Reiss, et al., "Safety of Non-Nucleoside Reverse Transcriptase Therapy: Data from the EUROSIDA Study [Abstract 24]," In: Abstracts of the 5th International Workshop on Adverse Drug Reactions and Lipodystrophy in HIV (Paris). Antiviral Therapy, Vol. 8, 2003, p. L20.

[48] A. L. Pozniak, R. Miller and L. P. Ormerod, "The Treatment of Tuberculosis in HIV-Infected Persons," AIDS, Vol. 13, No. 4, 1999, pp. 435-45. doi:10.1097/00002030-199903110-00001

[49] P. Piliero and B. Purdy, "Nevirapine-Induced Hepatitis: A Case Series and Review of the Literature," AIDS Reader, Vol. 11, No. 7, 2001, pp. 379-382.

[50] D. Dieterich, S. Becker, J. Fusco, et al., "Low Incidence of Grade III/IV Hepatotoxicity in First HAART Observations from 1237 Patients Followed for One Year (Poster 4534)," Program and Abstracts of the XIV Conference of the International AIDS Society (Barcelona), 2002.

[51] S. Becker, "Liver Toxicity in Epidemiological Cohorts," Clinical Infectious Diseases, Vol. 38, Suppl. 2, 2004, pp. S49-55. doi:10.1086/381447

[52] S. Imperiale, S. Lanes, J. Stern, J. Love, P. Robinson and D. Mayers, "TARGET: Incidence of Elevated ALT/AST with HAART in a Large Observational Cohort [Abstract P150]," Program and Abstracts of the 6th International Congress on Drug Therapy in HIV Infection (Glasgow). 2002, p. 150.

[53] S. Clarke, P. Harrington, M. Barry and F. Mulcahy, "The Tolerability of Efavirenz after Nevirapine-Related Adverse Events," Clinical Infectious Diseases, Vol. 31, No. 3, 2000, pp. 806-807. doi:10.1086/314026

[54] V. Soriano, C. Dona, P. Barreiro and J. Gonzalez-Lahoz, 
"Is There Cross-Toxicity between Nevirapine and Efavirenz in Subjects Developing Rash?" AIDS, Vol. 14, No. 11, 2000, pp. 1672-1673.

doi:10.1097/00002030-200007280-00032

[55] W. Manosuthi, S. Thongyen, N. Chumpathat, K. Muang- chana and S. Sungkanuparph, "Incidence and Risk Factors of Rash Associated with Efavirenz in HIV-Infected Patients with Preceding Nevirapine-Associated Rash," HIV Medicine, Vol. 7, No. 6, 2006, pp. 378-382. doi:10.1111/j.1468-1293.2006.00396.x 